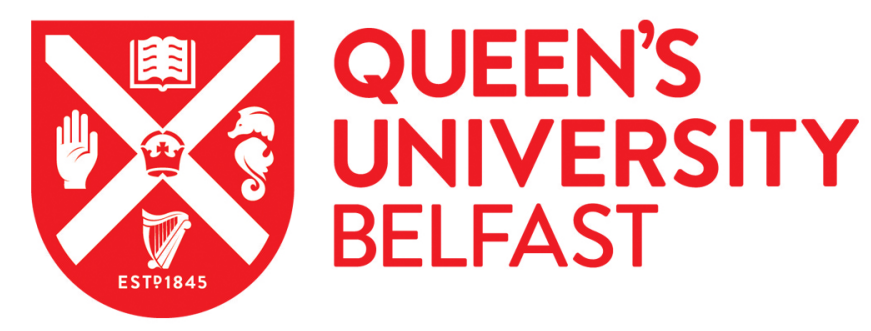

\title{
Borderline estrogen receptor-positive breast cancers in black and white women
}

Benefield, H. C., Allott, E. H., Reeder-Hayes, K. E., Perou, C. M., Carey, L. A., Geradts, J., Sun, X., Calhoun, B. C., \& Troester, M. A. (2019). Borderline estrogen receptor-positive breast cancers in black and white women. Journal of the National Cancer Institute. https://doi.org/10.1093/jnci/djz206

Published in:

Journal of the National Cancer Institute

Document Version:

Peer reviewed version

Queen's University Belfast - Research Portal:

Link to publication record in Queen's University Belfast Research Portal

Publisher rights

(c) The Author(s) 2019. Published by Oxford University Press. All rights reserved.

This work is made available online in accordance with the publisher's policies. Please refer to any applicable terms of use of the publisher.

\section{General rights}

Copyright for the publications made accessible via the Queen's University Belfast Research Portal is retained by the author(s) and / or other copyright owners and it is a condition of accessing these publications that users recognise and abide by the legal requirements associated with these rights.

Take down policy

The Research Portal is Queen's institutional repository that provides access to Queen's research output. Every effort has been made to ensure that content in the Research Portal does not infringe any person's rights, or applicable UK laws. If you discover content in the Research Portal that you believe breaches copyright or violates any law, please contact openaccess@qub.ac.uk. 


\section{Article}

\section{Borderline estrogen receptor-positive breast cancers in black and white women}

Halei C. Benefield, PhD, Emma H. Allott, PhD, Katherine E. Reeder-Hayes, MD, Charles M. Perou, PhD, Lisa A. Carey, MD, Joseph Geradts, MD, Xuezheng Sun, PhD, Benjamin C. Calhoun, MD, PhD, Melissa A. Troester, $\mathrm{PhD}$

Affiliations: HCB, MAT, XS - Department of Epidemiology, Gillings School of Global Public Health, University of North Carolina at Chapel Hill, Chapel Hill, NC, USA; EHA - Centre for Cancer Research and Cell Biology, Queen's University Belfast, Belfast, Northern Ireland, United Kingdom; KRH, LAC - Department of Medical Oncology, UNC Lineberger Comprehensive Cancer Center, University of North Carolina at Chapel Hill, Chapel Hill, NC, USA; CMP Department of Genetics, University of North Carolina at Chapel Hill, Chapel Hill, NC, USA; JG - City of Hope National Medical Center, Department of Population Sciences, Duarte, CA, USA; BCC - Department of Pathology and Laboratory Medicine, UNC Lineberger Comprehensive Cancer Center, University of North Carolina at Chapel Hill, Chapel Hill, NC, USA; EHA Centre for Cancer Research and Cell Biology, Queen's University Belfast, Belfast, Northern Ireland, United Kingdom 
Corresponding author: Melissa A. Troester, 253 Rosenau Hall, CB \#7435, 135 Dauer Dr.

Chapel Hill, NC 27599- 7400, Phone 919-966-7408, Fax 919-966-7408, Email

$\underline{\text { troester@email.unc.edu }}$

Abbreviations: relative frequency differences (RFD), hazard ratio (HR), Carolina Breast Cancer Study (CBCS), risk of recurrence, Proliferation and Tumor size weighted (ROR-PT), human epidermal growth factor receptor 2 (HER2), estrogen receptor (ER), progesterone receptor (PR), ribonucleic acid (RNA), immunohistochemistry (IHC), formalin-fixed paraffin-embedded (FFPE), University of North Carolina at Chapel Hill (UNC)

Keywords: breast cancer, African Americans, estrogen receptor, recurrence, health status disparities 


\begin{abstract}
Background: Some breast tumors expressing $\geq 1 \%$ and $<10 \%$ estrogen receptor (ER) positivity ("ER-borderline") are clinically aggressive; others exhibit luminal biology. Prior ER-borderline studies included few black participants.
\end{abstract}

Methods: Using the Carolina Breast Cancer Study (Phase 1: 1993 - 1996, 2: 1996 - 2001, 3: 2008-2013), a population-based study that oversampled black women, we compared ERborderline $(n=217)$ to ER-positive $(n=1,885)$ and ER-negative $(n=757)$ tumors. PAM50 subtype and risk of recurrence score (ROR-PT, incorporates subtype, proliferation, tumor size) were measured. Relative frequency differences (RFD) were estimated using multivariable linear regression. Disease-free interval (DFI) was evaluated by ER category and endocrine therapy receipt, overall and by race using Kaplan Meier and Cox models. Statistical tests were two-sided. Results: ER-borderlines were more frequently Basal-like (RFD= +37.7\%, 95\% CI=27.1, 48.4) and high $\mathrm{ROR}-\mathrm{PT}(\mathrm{RFD}=+52.4 \%, 95 \% \mathrm{CI}=36.8,68.0)$ relative to ER-positives. Having a high ROR-PT ER-borderline tumor was statistically significantly associated with black race (RFD= $+26.2 \%, 95 \% \mathrm{CI}=9.0,43.3)$. Compared to ER-positives, DFI of ER-borderlines treated with endocrine therapy was poorer but not statistically significantly different (hazard ratio $[\mathrm{HR}]=2.03$, 95\% CI=0.89, 4.65), whereas DFI was statistically significantly worse for ER-borderlines without endocrine therapy $(\mathrm{HR}=3.33,95 \% \mathrm{CI}=1.84,6.02)$. However, black women with ERborderline had worse DFI compared to ER-positives, even when treated with endocrine therapy $(\mathrm{HR}=2.77,95 \% \mathrm{CI}=1.09,7.04)$.

Conclusions: ER-borderline tumors were genomically heterogeneous with survival outcomes that differed by endocrine therapy receipt and race. Black race predicted high-risk ERborderlines and may be associated with poorer endocrine therapy response. 
Estrogen receptor (ER) positivity is a prognostic indicator and a powerful predictor of endocrine therapy response in breast cancer. ${ }^{1-4}$ ER status is typically assessed using immunohistochemical (IHC) stains, from which percent and intensity of positively-stained tumor cells can be quantified. In most tumors, ER is either entirely absent or clearly expressed. ${ }^{5,6}$ However, a small subset of breast tumors exhibits weak $(\geq 1-<10 \%)$ ER-positivity. Many of these so-called "borderline" tumors have pathological features of ER-negative tumors, with survival outcomes intermediate between ER-negative and ER-positive cases. ${ }^{7-15}$ As a result, identifying ER-borderline tumors that are responsive to endocrine therapy has been a persistent clinical challenge. In 2010, the American Society of Clinical Oncology and College of American Pathologists issued clinical guidelines classifying ER-positive breast cancers as those with $\geq 1 \%$ staining; in these tumors endocrine therapy is recommended. ${ }^{16}$ Prior to these guidelines, many clinicians and investigators used $\geq 10 \%$ ER positivity to determine eligibility for endocrine therapy. ${ }^{17-19}$ The evidence supporting the 2010 change in ER threshold was largely derived from clinical trials with low representation of minority women. ${ }^{18-20}$

The Carolina Breast Cancer Study (CBCS) Phase 3 enrolled black and white women with invasive breast cancer from 2008-2013, spanning the 2010 change in clinical guidelines for ERpositivity. This allows a unique opportunity to evaluate ER-borderline outcomes comparing women with guideline concordant care excluding and including endocrine therapy. Moreover, the study is well-positioned to evaluate the role of both race and genomics in ER-borderline breast cancer. The study oversampled black women and conducted genomic profiling to measure intrinsic subtype and risk of recurrence scores.

In this study we compared the genomic features of ER-borderline tumors to ER-positive and ER-negative tumors in Phases 1,2, and 3 of the CBCS and analyzed disease free interval 
(DFI) of women enrolled in Phase 3 to evaluate outcomes of ER-borderline tumors treated with and without endocrine therapy. This work identifies demographic and clinical characteristics associated with poor prognosis molecular features and assesses whether ER-borderline recurrence rates differ by race or initiation of endocrine therapy.

\section{Methods}

\section{Study population}

The CBCS is a population-based study conducted in North Carolina (Phase 1: 1993-1996, Phase 2: 1996-2001 and Phase 3: 2008-2013); study details have been described previously. ${ }^{21,22}$ Supplementary Figure 1 depicts study population inclusion. Briefly, women aged $20-74$ years diagnosed with a first primary invasive breast cancer were enrolled using rapid case ascertainment, oversampling black and younger women (age <50). Health history was collected during in-home interviews. ${ }^{23,24}$ Race was self-reported and categorized as white or black. Less than $2 \%$ of non-black participants self-identified as multiracial, Hispanic or other race/ethnicities and were grouped with white cases for statistical analyses. The study was approved by the Office of Human Research Ethics at the University of North Carolina at Chapel Hill (UNC). Informed consent was obtained from each participant.

\section{Tumor characteristics}

Tumor size, node status, and stage were abstracted from medical records and pathology reports. Combined grade was centrally assigned by a single breast cancer pathologist (JG) using the Nottingham breast cancer grading system. ${ }^{25}$ Grade was missing for Phase 2. PR status was determined from medical record in $80 \%$ of cases from Phases 1 and 2, and from IHC staining at 
UNC for remaining cases. Human epidermal growth factor receptor 2 (HER2) status was determined by IHC staining at UNC for Phases 1 and 2 and pathology reports for Phase $3{ }^{24}$

\section{ER categories}

Quantitative ER data were available for 2,859 cases. ER expression was abstracted from medical and pathology records for 496 cases (17\%) from Phases 1 and 2. Quality assurance studies in CBCS found high accuracy in clinical data ascertainment. ${ }^{24}$ For remaining cases, formalin-fixed paraffin-embedded (FFPE) tumor tissue blocks were previously sectioned and IHC stained at the Translational Pathology Laboratory at UNC. ${ }^{26}$ For 1,685 cases, multiple tissue microarray cores per case were assessed using automated algorithms (Aperio Technologies, Vista, CA). A core-to-case collapsing method was applied to determine ER percent positivity using a tumor cellularity-weighted approach. Agreement with clinical record was $93 \% .{ }^{26}$ For 679 cases, whole slides were assessed by automated algorithm. Agreement with clinical record was $81 \%$ for Phases 1 and 2 and found to be $89 \%$ for Phase $3 .{ }^{24}$ For all cases, ER category was defined by percent of cells staining positively for ER at any intensity, with $<1 \%$ negative, $\geq 1-$ $<10 \%$ borderline, and $\geq 10 \%$ positive.

\section{Genomic assessment}

The details of ribonucleic acid (RNA) isolation and quantification have been published previously. ${ }^{27}$ Briefly, at UNC central laboratory, RNA was isolated from FFPE tumor blocks using Qiagen FFPE RNeasy kit and quantified using NanoString assay. ${ }^{28}$ Data that passed quality control using NanoString nSolver software were normalized following nCounter protocol, including background subtraction, positive control normalization, and reference gene normalization. Normalized data was $\log 2$ transformed, standardized across samples, and median 
centered across genes. Genomic analysis was performed for all participants with tumor blocks available. Relative to participants without genomic data, those with genomic data had larger tumors, higher tumor stage, higher grade, and were more likely to be lymph node positive. There was no statistically significant difference in age at diagnosis.

P53 status was assessed using a previously validated 52-gene TP53-dependent signature. ${ }^{29}$ Mutant-like vs. normal-like class was determined by similarity-to-centroid approach using Distance Weighted Discrimination. ${ }^{30}$ ESRl expression was measured using an ESRIspecific probe and NanoString RNA counting methods.

As described previously, PAM50 predictor was used to categorize tumors as Luminal A, Luminal B, HER2-enriched, Basal-like, and normal-like and to calculate risk of recurrence score (ROR-PT), which incorporates subtype with additional weighting by a proliferation gene signature and tumor size. ${ }^{27,31}$ The ROR-PT score predicts individual risk of distant recurrence ${ }^{32,33}$ Normal-like samples were excluded due to insufficient tumor cellularity $(n=50)$.

\section{Breast cancer recurrence}

Recurrence data were available only for Phase 3 ( $n=2157)$. Disease-free interval (DFI) was defined as time from diagnosis to subsequent recurrent breast cancer (local, regional, or distant). ${ }^{34}$ Breast cancer recurrence, including date, was verified using the medical records of women who reported having a recurrence during telephone follow-up contact, which occurred at 9, 18, 38, 66, 80, 92 and 104 months from enrollment. Recurrence data in this analysis is complete through September 2018. We excluded women with stage IV disease at first diagnosis $(n=65)$, ER-positive women who did not receive endocrine therapy $(n=100)$, and ER-negative women who received endocrine therapy $(n=56)$. HER2-positive $(n=297)$ and missing HER2 
status $(n=2)$ were excluded. ER-borderlines were grouped by endocrine therapy receipt $(n=36$ received endocrine therapy, $\mathrm{n}=58 \mathrm{did}$ not). Chemotherapy receipt was assessed. We performed a sensitivity analyses excluding 30 women who experienced a recurrence within one year of their first primary breast cancer diagnosis.

\section{Statistical analyses}

Linear binomial regression was used to calculate relative frequency differences (RFD), interpretable as the percentage difference between index and referent groups, and $95 \%$ confidence intervals $(95 \% \mathrm{CI})$. P-values were from two-sided Chi-square tests with $\alpha=0.05$.

Finite mixture modeling was used to dichotomize tumors as ESRl-high and ESR1low. ${ }^{35,36}$ Using the expectation-maximization algorithm described by Do et al., we estimated parameters that minimized model deviance and assigned a cutoff as the value at which the probability of belonging to the low-ESRl peak was equivalent to a type-I error at $0.05 .{ }^{37}$ Cutoff selection was performed using R version 3.4.3 (R Foundation for Statistical Computing, Vienna, Austria). Median ESRI expression levels were compared using Kruskal-Wallis test.

We used multiple linear regression to test whether receipt of endocrine therapy among ER-borderlines was associated with clinical variables. Kaplan Meier curves of DFI were compared using log-rank test with Bonferroni correction $(\alpha / 6)$ for multiple comparisons. Pvalues comparing 5-year recurrence rates were calculated using z-test, assuming normal distribution using the difference of the two rates and standard errors. ${ }^{38}$ Multivariable Cox proportional hazards models were used to estimate associations between DFI (outcome) and 4 categories of exposure: ER-positive, ER-borderline with endocrine therapy, ER-borderline without endocrine therapy, and ER-negative. Model 1 adjusted for age and stage. Model 2 
additionally adjusted for chemotherapy receipt. Proportional hazards assumptions were assessed visually and found to be valid. Addition of PR status did not substantially change effect estimates (data not shown). We tested for statistical interaction between race and exposure category using likelihood ratio test $(\alpha=0.10)$. Statistical analyses were conducted using SAS version 9.4 (SAS Institute Inc., Cary, NC, USA).

\section{Results}

\section{Clinical, demographic, and genomic features of ER-borderline tumors}

We first examined clinical and demographic features by ER category in all three phases of CBCS. The 2,859 eligible participants included 1,509 (52.8\%) white and 1,350 (47.2\%) black women. $7.6 \%(n=217)$ of cases were ER-borderline, $26.5 \%(n=757)$ were ER-negative, and $65.9 \%(n=1,885)$ were ER-positive. Both ER-negatives and ER-borderlines exhibited a statistically significantly younger age at diagnosis and were more common among premenopausal women compared to ER-positives. Frequency of ER-borderline tumors did not vary by race. Both ER-negatives and ER-borderlines were more frequently high grade (Table 1).

We next analyzed gene expression profiles of tumors from Phases $1-3$ to compare molecular features by ER category. Genomic data were available for 1,508 cases. Intrinsic subtype distribution among ER-borderlines was mixed. ER-negatives and ER-borderlines had a statistically significantly higher frequency of HER2-enriched (17.7\% ER-negative, RFD: $+67.5 \%, 95 \%$ CI 58.6, 76.4, p-value < 0.001; 1.3\% ER-borderline, RFD: $+27.2 \%, 95 \%$ CI 12.2, 42.2, p-value <0.001; two-sided Chi-square test ) and Basal-like subtypes (71.7\% ER-negative, RFD: $+80.3 \%, 95 \%$ CI 76.1, 84.4, p-value < 0.001; 41.8\% ER-borderline, RFD: $+37.7 \%, 95 \%$ 
CI 27.1, 48.4, p-value < 0.001; two-sided Chi-square test ) relative to ER-positive (2.7\% HER2enriched, 5.1\% Basal-like) (Figure 1). The relative frequency of high ROR-PT score was statistically significantly higher for both ER-negatives (RFD: 67.9\%, 95\% CI 61.9, 73.8, p < 0.001) and ER-borderlines (RFD: $+52.4 \%, 95 \%$ CI 36.8, 68.0, p < 0.001) versus ER-positives (Table 2).

ER-borderlines also varied with respect to p53 status and quantitative ESR1. Both ERnegative and ER-borderline tumors were more likely to be p53 mutant-like and ESR I-low than ER-positive tumors. Median ESRl expression level of ER-borderline was statistically significantly different from ER-negative (p-value <0.001, Kruskal-Wallis test) and ER-positive (p-value <0.001, Kruskal-Wallis test) with highest expression among ER-positives (median 10.3, interquartile range 9.3 - 11.3) followed by ER-borderlines (median 7.1, interquartile range 4.9 9.3) then ER-negatives (median 5.1, interquartile range 4.0 - 6.6) (Supplementary Figure 2).

We next assessed whether demographic and clinical variables could identify ERborderline tumors with poor-prognosis genomic features in Phases 1 - 3. Black race was statistically significantly associated with high ROR-PT among borderline tumors $(38.8 \%$ black vs $12.5 \%$ white women, RFD $+26.2 \%, 95 \%$ CI 9.0, 43.3) (Table 3). High tumor grade was statistically significantly associated with ER-borderlines of Basal-like subtype (55\% high vs $15 \%$ low/medium grade, RFD: $+41.9 \%, 95 \%$ CI 17.7, 66.0).

\section{ER-borderline tumor association with recurrence outcomes}

Phase 3 enrollment spanned 2008-2013 and included women with HER2-negative ERborderline tumors who received treatment with and without endocrine therapy. ${ }^{16}$ The recurrence rates for these tumors were compared to those of ER-negatives treated without endocrine therapy 
and ER-positives treated with endocrine therapy. A total of 189 recurrences occurred over median follow-up of 6.69 years (range $=0.40$ to 9.96$)$. Chemotherapy use was $83 \%(n=48)$ among ER-borderlines without endocrine therapy, $70 \%(n=25)$ among ER-borderlines with endocrine therapy, 91\% ( $\mathrm{n}=348)$ among ER-negatives and 47\% ( $\mathrm{n}=548)$ among ER-positives. Receipt of endocrine therapy among borderlines was statistically significantly associated with PR-positive status, but not with race, age, year of diagnosis, menopausal status, or stage. ERnegatives and ER-borderlines without endocrine therapy had statistically significantly worse DFI relative to ER-positives, but DFI was not statistically significantly different between ERpositives and ER-borderlines that initiated endocrine therapy (Figure 2). Five-year DFI probability was $93.7 \%$ (95\% CI: 92.2, 95.1) for ER-positives, 88.2\% (95\% CI: 77.3, 99.1, p= 0.32 compared to ER-positive, z-test) for ER-borderlines with endocrine therapy,77.3\% for ERborderlines without endocrine therapy (95\% CI: 66.4, 88.1, p = 0.002 compared to ER-positive, $\mathrm{z}$ test) and $80.7 \%$ for ER-negatives (95\% CI: 76.7, 84.7, $\mathrm{p}=<0.001$ compared to ER-positive, $\mathrm{z}$ test). Compared to ER-positives, hazard of recurrence for ER-borderlines with endocrine therapy was poorer but not statistically different (HR: 2.03, 95\% CI 0.89, 4.65), whereas ER-borderlines without endocrine therapy fared statistically significantly worse (HR: 3.33, 95\% CI 1.84, 6.02) (Table 4).

DFI was also examined cross-classified on ER category and race, with results suggesting possible interaction between the two (likelihood ratio test $\mathrm{p}$-value $=0.11$ ). Among white women, ER-borderlines with endocrine therapy had recurrence risk similar to ER positives $(\mathrm{HR}=0.99$, 95\% $\mathrm{CI}=0.14,7.19$, adjusted for age, stage, and chemotherapy receipt) while ER-borderlines without endocrine therapy had statistically significantly worse DFI $(\mathrm{HR}=4.22,95 \% \mathrm{CI}=1.75$, 10.23, adjusted for age, stage, and chemotherapy receipt) (Figure 3). Black women with ER- 
borderline, however, experienced worse DFI regardless of endocrine therapy receipt (Figure 4). Black women with ER-borderline receiving endocrine therapy had a HR of 2.77 (95\% CI=1.09, 7.04, adjusted for age, stage, and chemotherapy receipt); black women not receiving endocrine therapy had a HR of 2.53 (95\% CI=1.13, 5.70, adjusted for age, stage, and chemotherapy receipt)

(Table 4). Sensitivity analysis excluding 30 recurrences that occurred within one year of first primary diagnosis did not change the direction or statistical significance of effect estimates.

\section{Discussion}

This study evaluated clinical and genomic features of 217 breast tumors classified as $\geq 1-$ $<10 \%$ ER-positive in a large, racially diverse population-based cohort. Relative to ER-positive tumors, ER-borderlines shared many demographic and clinical characteristics with ER-negative tumors, including a higher frequency of younger and premenopausal women, high grade, high ROR-PT score, and p53 mutant-like status. However, genomic analyses revealed that ERborderline tumors are more heterogeneous with regard to intrinsic subtype than either ERnegative or ER-positive. DFI in ER-borderlines treated with endocrine therapy was intermediate between ER-negatives and ER-positives, while DFI in ER-borderlines without endocrine therapy was statistically significantly worse than ER-positives and statistically indistinguishable from ER-negatives. In race-stratified analyses, the benefit of endocrine therapy was evident for white women, but not for black women, who experienced statistically significantly worse DFI when diagnosed with ER-borderline, regardless of endocrine therapy receipt.

Our finding that ER-borderline tumors have genomic characteristics distinct from ERpositives is in line with earlier studies of mostly white women. Multi-gene RNA-based genomic characteristics have been reported in several cohorts of ER-borderline cases from clinical trials 
or academic referral centers. ${ }^{7,8,14,15}$ Our proportion of borderlines, representing only $8 \%$ of breast cancers, is consistent with those in earlier reports, which have found the frequency of ERborderlines to range from 3\% to 13\%; Supplementary Table 1 summarizes prior studies for comparison. $^{7-9,14,39,40}$ The distribution of intrinsic subtypes observed among ER-borderlines resembles a mixture of that seen in the other two ER categories. Here we report 44\% Luminal, with the remainder comprised of HER2-enriched and Basal-like subtype. This closely aligns with Cheang et al., who found $60 \%$ of ER $1-9 \%$ positive tumors $(n=65)$ were Basal-like and HER2enriched subtype. ${ }^{8}$ In contrast, Iwamoto et al. reported 92\% Basal-like and HER2-enriched subtype among ER $1-9 \%$ positive cases $(n=25)$, which may be due to the higher proportion of advanced tumors in their study (50\% of ER $1-9 \%$ were $>5 \mathrm{~cm}$ in size versus $9 \%$ in this study). ${ }^{7}$ Iwamoto et al. also found that ER $1-9 \%$ tumors had ESRI expression values similar to ERnegatives, while we found that ER-borderline ESRl expression is statistically distinct from both ER-negative and ER-positive tumors. This suggests a mixed nature of the intrinsic subtype distribution among ER-borderlines.

Because clinical guidelines for ER-positivity changed during the enrollment period of CBCS Phase 3 (2008 - 2013), our study allowed for analysis of ER-borderline outcomes with and without endocrine therapy initiation. Consistent with prior studies, we found that among all women, ER-borderlines that were treated with endocrine therapy exhibited recurrence rates that were not statistically different from ER-positive tumors, while ER-borderlines that did not receive endocrine therapy had recurrence rates similar to ER-negatives and statistically significantly different from ER-positives. This finding may reflect a true association between endocrine therapy and ER-borderline outcomes but it is important to recognize that patients in 
this observational study were not randomized. Patients not receiving endocrine therapy may have been under-treated in other modalities, which were not accounted for in our analysis.

The genomic features and survival outcomes of ER-borderline tumors among black and white women have not been previously examined. Though our race-stratified analyses were limited in precision due to small numbers of participants, the lack of endocrine therapy benefit among black women with ER-borderline tumors may indicate an important disparity. This disparity may reflect differences in tumor biology as indicated by higher ROR-PT scores among ER-borderline black women, but may also reflect different rates of endocrine therapy adherence between black and white women. In previous work in CBCS, black women undergoing endocrine therapy experienced a larger burden of side effects and were more likely to report nonadherence than white women. ${ }^{41}$ Understanding the factors contributing to endocrine therapy nonadherence will be critical to optimizing treatment delivery for all women.

This study has several strengths, including its large cohort of nearly $50 \%$ black and white women, enabling a population-based estimate of the prevalence of ER-borderline breast cancer. We also had detailed treatment and follow-up data, and centralized genomic analyses. However, these findings are subject to some limitations. First, there are likely factors not accounted for in this analysis that may influence the association between ER-borderline status and risk of recurrence, such as additional treatment modalities, adherence to endocrine therapy, duration of therapy, and time from diagnosis to treatment. Second, our follow-up data are not yet mature enough to include overall or breast cancer-specific survival, or late recurrences. Thus, this analysis reflects patterns within the early window following diagnosis. Finally, ER-borderline is a relatively uncommon breast cancer phenotype. Consequently, while our study is larger than previous studies of ER-borderline tumor genomics, the small number of ER-borderline tumors 
precluded a more detailed stratification of recurrence by genomic subtype and resulted in low precision in race-stratified analyses. Nonetheless, this study contributes valuable insight to the small subset of breast cancer cases with low percent positivity of ER.

In summary, we found that while many ER-borderline tumors share similarities with ERnegative tumors, these tumors are, as a group, heterogeneous. Black race and high grade at diagnosis predicted high-risk tumor characteristics among ER-borderline cases. Furthermore, we found that while white women with ER-borderline who received endocrine therapy had recurrence risk similar to ER-positives, black women with ER-borderline experienced higher recurrence risk regardless of endocrine therapy receipt. Further work is needed to understand how biology and treatment adherence interact to produce disparities in outcomes for black women.

\section{Funding}

This work was supported by a grant from the UNC Lineberger Comprehensive Cancer Center funded by the University Cancer Research Fund (LCCC2017T204), Susan G. Komen

Foundation, the National Cancer Institute of the National Institutes of Health (P50-CA58223, U01-CA179715 to MAT and CMP, T32-CA057726 to HCB, F30-CA236199 to HCB), the National Institute of Environmental Health Sciences of the National Institutes of Health (P30ES010126 to MAT). HCB is a recipient of the Gertrude B. Elion Mentored Medical Student Research Award of Triangle Community Foundation. 


\section{Notes}

Prior presentation: Presented at the 2018 San Antonio Breast Cancer Symposium, San Antonio, TX, Dec 4-8, 2018.

Disclaimers: CMP is an equity stock holder, consultant, and Board of Director Member, of BioClassifier LLC and GeneCentric Diagnostics. CMP is also listed an inventor on patent applications on the Breast PAM50 assay.

Role of the funder: This content is solely the responsibility of the authors and does not necessarily represent the official views of the National Institutes of Health. The funder had no role in study design, data collection, analysis or interpretation, or writing of the manuscript.

\section{References}

1. Elledge R, Allred D. Clinical aspects of estrogen and progesterone receptors. In: Diseases of the Breast. 3rd ed. ; 2004:602-617.

2. Bartlett JMS, Brookes CL, Robson T, et al. Estrogen receptor and progesterone receptor as predictive biomarkers of response to endocrine therapy: a prospectively powered pathology study in the Tamoxifen and Exemestane Adjuvant Multinational trial. J Clin Oncol. 2011;29(12):1531-1538. doi:10.1200/JCO.2010.30.3677

3. Harvey JM, Clark GM, Osborne CK, Allred DC. Estrogen receptor status by immunohistochemistry is superior to the ligand-binding assay for predicting response to adjuvant endocrine therapy in breast cancer. J Clin Oncol. 1999;17(5):1474-1481. doi:10.1200/JCO.1999.17.5.1474 
4. Pertschuk LP, Kim DS, Nayer K, et al. Immunocytochemical estrogen and progestin receptor assays in breast cancer with monoclonal antibodies. Histopathologic, demographic, and biochemical correlations and relationship to endocrine response and survival. Cancer. 1990;66(8):1663-1670.

5. Collins LC, Botero ML, Schnitt SJ. Bimodal frequency distribution of estrogen receptor immunohistochemical staining results in breast cancer: an analysis of 825 cases. Am J Clin Pathol. 2005;123(1):16-20.

6. Nadji M, Gomez-Fernandez C, Ganjei-Azar P, Morales AR. Immunohistochemistry of estrogen and progesterone receptors reconsidered: experience with 5,993 breast cancers. Am J Clin Pathol. 2005;123(1):21-27.

7. Iwamoto T, Booser D, Valero V, et al. Estrogen Receptor (ER) mRNA and ER-Related Gene Expression in Breast Cancers That Are $1 \%$ to $10 \%$ ER-Positive by Immunohistochemistry. J Clin Oncol. 2012;30(7):729-734. doi:10.1200/JCO.2011.36.2574

8. Cheang MCU, Martin M, Nielsen TO, et al. Defining Breast Cancer Intrinsic Subtypes by Quantitative Receptor Expression. Oncologist. 2015;20(5):474-482.

doi:10.1634/theoncologist.2014-0372

9. Yi M, Huo L, Koenig KB, et al. Which threshold for ER positivity? a retrospective study based on 9639 patients. Ann Oncol Off J Eur Soc Med Oncol. 2014;25(5):1004-1011. doi:10.1093/annonc/mdu053

10. Fujii T, Kogawa T, Dong W, et al. Revisiting the definition of estrogen receptor positivity in HER2-negative primary breast cancer. Ann Oncol. 2017;28(10):2420-2428. 
doi:10.1093/annonc/mdx397

11. Raghav KPS, Hernandez-Aya LF, Lei X, et al. Impact of low estrogen/progesterone receptor expression on survival outcomes in breast cancers previously classified as triple negative breast cancers. Cancer. 2012;118(6):1498-1506. doi:10.1002/cncr.26431

12. Landmann A, Farrugia DJ, Zhu L, et al. Low Estrogen Receptor (ER)-Positive Breast Cancer and Neoadjuvant Systemic Chemotherapy. Am J Clin Pathol. 2018;150(1):34-42. doi:10.1093/ajcp/aqy028

13. Balduzzi A, Bagnardi V, Rotmensz N, et al. Survival Outcomes in Breast Cancer Patients With Low Estrogen/Progesterone Receptor Expression. Clin Breast Cancer. 2014;14(4):258-264. doi:10.1016/j.clbc.2013.10.019

14. Deyarmin B, Kane JL, Valente AL, et al. Effect of ASCO/CAP Guidelines for Determining ER Status on Molecular Subtype. Ann Surg Oncol. 2013;20(1):87-93. doi:10.1245/s10434-012-2588-8

15. Sheffield BS, Kos Z, Asleh-Aburaya K, et al. Molecular subtype profiling of invasive breast cancers weakly positive for estrogen receptor. Breast Cancer Res Treat. 2016;155(3):483-490. doi:10.1007/s10549-016-3689-z

16. Hammond MEH, Hayes DF, Dowsett M, et al. American Society of Clinical Oncology/College of American Pathologists Guideline Recommendations for Immunohistochemical Testing of Estrogen and Progesterone Receptors in Breast Cancer. J Clin Oncol. 2010;28(16):2784-2795. doi:10.1200/JCO.2009.25.6529

17. Elledge RM, Green S, Pugh R, et al. Estrogen receptor (ER) and progesterone receptor 
(PgR), by ligand-binding assay compared with ER, PgR and pS2, by immunohistochemistry in predicting response to tamoxifen in metastatic breast cancer: a Southwest Oncology Group Study. Int J cancer. 2000;89(2):111-117.

18. Regan MM, Viale G, Mastropasqua MG, et al. Re-evaluating adjuvant breast cancer trials: Assessing hormone receptor status by immunohistochemical versus extraction assays. $J$ Natl Cancer Inst. 2006;98(21):1571-1581. doi:10.1093/jnci/djj415

19. Dowsett M, Allred C, Knox J, et al. Relationship Between Quantitative Estrogen and Progesterone Receptor Expression and Human Epidermal Growth Factor Receptor 2 (HER-2) Status With Recurrence in the Arimidex, Tamoxifen, Alone or in Combination Trial. J Clin Oncol. 2008;26(7):1059-1065. doi:10.1200/JCO.2007.12.9437

20. Harvey JM, Clark GM, Osborne CK, Allred DC. Estrogen Receptor Status by Immunohistochemistry Is Superior to the Ligand-Binding Assay for Predicting Response to Adjuvant Endocrine Therapy in Breast Cancer. J Clin Oncol. 1999;17(5):1474-1474. doi:10.1200/JCO.1999.17.5.1474

21. Newman B, Moorman PG, Millikan R, et al. The Carolina Breast Cancer Study: integrating population-based epidemiology and molecular biology. Breast Cancer Res Treat. 1995;35(1):51-60.

22. Hair BY, Hayes S, Tse C-K, Bell MB, Olshan AF. Racial differences in physical activity among breast cancer survivors: implications for breast cancer care. Cancer. 2014;120(14):2174-2182. doi:10.1002/cncr.28630

23. Millikan RC, Newman B, Tse C-K, et al. Epidemiology of basal-like breast cancer. Breast Cancer Res Treat. 2008;109(1):123-139. doi:10.1007/s10549-007-9632-6 
24. Carey LA, Perou CM, Livasy CA, et al. Race, Breast Cancer Subtypes, and Survival in the Carolina Breast Cancer Study. JAMA. 2006;295(21):2492. doi:10.1001/jama.295.21.2492

25. Elston CW, Ellis IO. Pathological prognostic factors in breast cancer. I. The value of histological grade in breast cancer: experience from a large study with long-term followup. Histopathology. 1991;19(5):403-410.

26. Allott EH, Cohen SM, Geradts J, et al. Performance of Three-Biomarker Immunohistochemistry for Intrinsic Breast Cancer Subtyping in the AMBER Consortium. Cancer Epidemiol Biomarkers Prev. 2016;25(3):470-478. doi:10.1158/1055-9965.EPI-150874

27. Troester MA, Sun X, Allott EH, et al. Racial Differences in PAM50 Subtypes in the Carolina Breast Cancer Study. JNCI J Natl Cancer Inst. 2018;110(2):176-182. doi:10.1093/jnci/djx135

28. Geiss GK, Bumgarner RE, Birditt B, et al. Direct multiplexed measurement of gene expression with color-coded probe pairs. Nat Biotechnol. 2008;26(3):317-325. doi:10.1038/nbt1385

29. Troester MA, Herschkowitz JI, Oh DS, et al. Gene expression patterns associated with p53 status in breast cancer. BMC Cancer. 2006;6:276. doi:10.1186/1471-2407-6-276

30. Marron JS, Todd MJ. Distance Weighted Discrimination. http://www.optimizationonline.org/DB_HTML/2002/07/513.html. Published 2002. Accessed January 10, 2018.

31. Parker JS, Mullins M, Cheang MCU, et al. Supervised risk predictor of breast cancer based on intrinsic subtypes. J Clin Oncol. 2009;27(8):1160-1167. 
doi:10.1200/JCO.2008.18.1370

32. Dowsett M, Sestak I, Lopez-Knowles E, et al. Comparison of PAM50 risk of recurrence score with oncotype DX and IHC4 for predicting risk of distant recurrence after endocrine therapy. J Clin Oncol. 2013;31(22):2783-2790. doi:10.1200/JCO.2012.46.1558

33. Gnant M, Filipits M, Greil R, et al. Predicting distant recurrence in receptor-positive breast cancer patients with limited clinicopathological risk: using the PAM50 Risk of Recurrence score in 1478 postmenopausal patients of the ABCSG-8 trial treated with adjuvant endocrine therapy alone. Ann Oncol. 2014;25(2):339-345. doi:10.1093/annonc/mdt494

34. Hudis CA, Barlow WE, Costantino JP, et al. Proposal for standardized definitions for efficacy end points in adjuvant breast cancer trials: the STEEP system. J Clin Oncol. 2007;25(15):2127-2132. doi:10.1200/JCO.2006.10.3523

35. Schlattmann P. Medical Applications of Finite Mixture Models. Berlin, Heidelberg: Springer Berlin Heidelberg; 2009. doi:10.1007/978-3-540-68651-4

36. TRANG N V., CHOISY M, NAKAGOMI T, et al. Determination of cut-off cycle threshold values in routine RT-PCR assays to assist differential diagnosis of norovirus in children hospitalized for acute gastroenteritis. Epidemiol Infect. 2015;143(15):3292-3299. doi:10.1017/S095026881500059X

37. Do CB, Batzoglou S. What is the expectation maximization algorithm? Nat Biotechnol. 2008;26(8):897-899. doi:10.1038/nbt1406

38. Parkin DM, Hakulinen T. Cancer registration: principles and methods. Analysis of 
survival. IARC Sci Publ. 1991;(95):159-176.

39. Ogawa Y, Moriya T, Kato Y, et al. Immunohistochemical assessment for estrogen receptor and progesterone receptor status in breast cancer: analysis for a cut-off point as the predictor for endocrine therapy. Breast Cancer. 2004;11(3):267-275.

40. Chen T, Zhang N, Moran MS, Su P, Haffty BG, Yang Q. Borderline ER-Positive Primary Breast Cancer Gains No Significant Survival Benefit From Endocrine Therapy: A Systematic Review and Meta-Analysis. Clin Breast Cancer. 2018;18(1):1-8. doi:10.1016/j.clbc.2017.06.005

41. Wheeler SB, Spencer J, Pinheiro LC, et al. Endocrine Therapy Nonadherence and Discontinuation in Black and White Women. JNCI J Natl Cancer Inst. September 2018. doi:10.1093/jnci/djy136 
Tables

Table 1: Demographic and clinical characteristics of cases in Carolina Breast Cancer Study Phases 1, 2, and 3 by immunohistochemical-defined estrogen receptor (ER) category

\begin{tabular}{|c|c|c|c|}
\hline \multirow[b]{2}{*}{ Characteristic } & \multicolumn{3}{|c|}{ ER expression } \\
\hline & $\begin{array}{c}<1 \% \\
\mathrm{~N}=757(26.5 \%)\end{array}$ & $\begin{array}{c}\geq 1-<10 \% \\
\mathrm{~N}=217(7.6 \%)\end{array}$ & $\begin{array}{c}\geq 10 \% \\
\mathrm{~N}=1,885(65.9 \%)\end{array}$ \\
\hline \multicolumn{4}{|l|}{ Study Phase } \\
\hline 1 & $66(8.7)$ & $60(27.7)$ & $133(7.1)$ \\
\hline 2 & $150(19.8)$ & $17(7.8)$ & $276(14.6)$ \\
\hline 3 & $541(71.5)$ & $140(64.5)$ & $1476(78.3)$ \\
\hline \multicolumn{4}{|l|}{ Age at diagnosis } \\
\hline$<50$ (ref) & $432(57.1)$ & $127(58.5)$ & $857(45.5)$ \\
\hline$\geq 50$ & $325(42.9)$ & $90(41.5)$ & $1028(54.5)$ \\
\hline $\mathrm{RFD}^{*}(95 \% \mathrm{CI})$ & $-9.6 \%(-12.9,-6.3)$ & $-4.9 \%(-7.7,-2.3)$ & REF \\
\hline $\mathrm{p}^{\dagger}$ & $<0.001$ & $<0.001$ & \\
\hline \multicolumn{4}{|l|}{ Menopausal status, n (\%) } \\
\hline Premenopausal (ref) & $373(49.3)$ & $115(53.0)$ & 785 (41.6) \\
\hline Postmenopausal & $384(50.7)$ & $102(47.0)$ & $1,100(58.4)$ \\
\hline $\mathrm{RFD}^{*}(95 \% \mathrm{CI})$ & $-6.5 \%(-9.9,-3.2)$ & $-4.3 \%(-6.9,-1.6)$ & REF \\
\hline $\mathrm{p}^{\dagger}$ & $<0.001$ & 0.002 & \\
\hline \multicolumn{4}{|l|}{ Race, n (\%) } \\
\hline White (ref) & $288(38.0)$ & $118(54.4)$ & $1,103(58.5)$ \\
\hline AA/Black & $469(62.0)$ & $99(46.6)$ & $782(41.5)$ \\
\hline $\mathrm{RFD}^{*}(95 \% \mathrm{CI})$ & $16.1 \%(12.6,19.4)$ & $1.4 \%(-1.1,3.9)$ & REF \\
\hline $\mathrm{p}^{\dagger}$ & $<0.001$ & 0.26 & \\
\hline \multicolumn{4}{|l|}{ PR Status } \\
\hline Positive (ref) & $86(11)$ & $96(44)$ & $1613(86)$ \\
\hline Negative & $665(89)$ & $121(56)$ & $264(14)$ \\
\hline $\mathrm{RFD}^{*}(95 \% \mathrm{CI})$ & $65.7 \%(62.5,68.9)$ & $25.6 \%(20.8,30.4)$ & REF \\
\hline $\mathrm{p}^{\dagger}$ & $<0.001$ & $<0.001$ & \\
\hline \multicolumn{4}{|l|}{ HER2 Status ${ }^{\S}$} \\
\hline Negative & $595(78.7)$ & $141(65.0)$ & $1427(75.8)$ \\
\hline Positive & $123(16.3)$ & $47(21.7)$ & $273(14.5)$ \\
\hline Missing & $38(5.0)$ & $29(13.3)$ & $183(9.7)$ \\
\hline \multicolumn{4}{|l|}{ Combined grade, $\mathrm{n}(\%)^{\|}$} \\
\hline 1 & $13(2.2)$ & $30(18.1)$ & $448(29.7)$ \\
\hline 2 & $84(14.4)$ & $45(27.1)$ & $711(47.2)$ \\
\hline 3 & $485(83.3)$ & $91(54.8)$ & $349(23.1)$ \\
\hline $\begin{array}{l}\text { RFD* (grade } 3 \text { vs grade } \\
1 / 2)(95 \% \mathrm{CI})\end{array}$ & $48.6 \%(44.8,52.5)$ & $13.6 \%(9.5,17.7)$ & REF \\
\hline $\mathrm{p}^{\dagger}$ & $<0.001$ & $<0.001$ & \\
\hline \multicolumn{4}{|l|}{ Tumor size $(\mathrm{cm}), \mathrm{n}(\%) \|$} \\
\hline$\leq 2$ & $318(42.8)$ & $99(46.7)$ & $1,130(60.7)$ \\
\hline$>2-\leq 5$ & $337(45.4)$ & $93(43.9)$ & $583(31.3)$ \\
\hline$>5$ & $88(11.8)$ & $20(9.4)$ & $149(8.0)$ \\
\hline $\begin{array}{l}\operatorname{RFD}^{*}(>2 \text { vs } \leq 2) \\
(95 \% \mathrm{CI})\end{array}$ & $5.7 \%(-0.7,12.2)$ & $0.0 \%(-5.1,5.1)$ & REF \\
\hline
\end{tabular}




\begin{tabular}{lccc}
$\mathrm{p}^{\dagger}$ & 0.08 & 0.99 \\
Node status, $\mathrm{n}(\%)^{\|}$ & & & \\
Negative (ref) & $448(59.4)$ & $134(62.0)$ & $1,187(63.2)$ \\
Positive & $306(40.6)$ & $82(38.0)$ & $691(36.8)$ \\
RFD $^{*}(95 \% \mathrm{CI})$ & $0.8 \%(-2.6,4.2)$ & $-0.3 \%(-2.9,2.3)$ & $\mathrm{REF}$ \\
$\mathrm{p}^{\dagger}$ & 0.64 & 0.82 & \\
Stage, $\mathrm{n}(\%)^{\|}$ & & & \\
I & $232(31.0)$ & $88(41.3)$ & $704(48.5)$ \\
II & $386(52.5)$ & $85(39.9)$ & $198(10.6)$ \\
III & $112(15.0)$ & $34(16.0)$ & $49(2.6)$ \\
IV & $19(2.5)$ & $6(2.8)$ & $\mathrm{REF}$ \\
RFD III/IV vs I/II & $4.9 \%(0,9.9)$ & $3.3 \%(-0.9,7.4)$ & \\
$(95 \% \mathrm{CI})$ & 0.05 & 0.13 & \\
$\mathrm{p}^{\dagger}$ & & & \\
\hline
\end{tabular}

*Relative frequency differences (RFD) adjusted for age and race (except for race models which were adjusted for age only and age and menopausal status models which were adjusted for race only). Abbreviations: estrogen receptor (ER), African American (AA), progesterone receptor (PR), human epidermal growth factor receptor 2 (HER2).

†Two-sided Chi-square test.

$\$ 14$ cases had missing PR status.

${ }^{\S}$ RFD not calculated due to uneven missingness across ER category.

"603 cases had missing grade, 42 had missing size, 11 had missing node status, 34 had missing stage. 
Table 2: Distribution of genomic tumor characteristics by immunohistochemical-defined estrogen receptor (ER) category in Carolina Breast Cancer Study Phases 1, 2, and 3

\begin{tabular}{|c|c|c|c|}
\hline \multirow[b]{2}{*}{ Characteristic } & \multicolumn{3}{|c|}{ ER expression } \\
\hline & $\begin{array}{c}<1 \% \\
\mathrm{~N}=422(28 \%)\end{array}$ & $\begin{array}{l}\geq 1-<10 \% \\
\mathrm{~N}=96(6 \%)\end{array}$ & $\begin{array}{c}\geq 10 \% \\
\mathrm{~N}=990(66 \%)\end{array}$ \\
\hline \multicolumn{4}{|l|}{ ROR-PT $^{*}$} \\
\hline Mean score (SD) & 60.24 (20.72) & $48.61(21.61)$ & $32.31(22.30)$ \\
\hline Low, No. $(\%)$ & $19(4.6)$ & $8(8.5)$ & $277(28.3)$ \\
\hline Medium & $217(52.0)$ & $62(66.0)$ & $622(63.5)$ \\
\hline High & $181(43.4)$ & $24(25.5)$ & $81(8.3)$ \\
\hline $\mathrm{RFD}^{\dagger}$ high vs low/medium (95\% & $67.9 \%(61.9,73.8)$ & $52.4 \%(36.8,68.0)$ & $\mathrm{REF}$ \\
\hline \multicolumn{4}{|l|}{ CI) } \\
\hline $\mathrm{p}^{\star}$ & $<0.001$ & $<0.001$ & \\
\hline \multicolumn{4}{|l|}{ p53 status, n (\%) } \\
\hline Wild-type (WT) & $155(36.7)$ & $49(51.0)$ & $722(72.9)$ \\
\hline Mutant-like & $267(63.3)$ & $47(49.0)$ & $268(27.1)$ \\
\hline $\mathrm{RFD}^{\dagger}$ mutant-like vs WT $(95 \% \mathrm{CI})$ & $29.8 \%(24.7,34.8)$ & $8.0 \%(3.8,12.2)$ & $\mathrm{REF}$ \\
\hline $\mathrm{p}^{\ddagger}$ & $<0.001$ & $<0.001$ & \\
\hline \multicolumn{4}{|l|}{ ESR1 expression } \\
\hline ESR1-low, n $(\%)^{\S}$ & $372(88.2)$ & $68(70.8)$ & $158(15.9)$ \\
\hline ESR1-high, n $(\%)^{\S}$ & $50(11.9)$ & $28(29.2)$ & $836(84.1)$ \\
\hline $\mathrm{RFD}^{\dagger}$ low vs high $(95 \% \mathrm{CI})$ & $63.2 \%(58.8,67.6)$ & $26.3 \%(20.2,32.5)$ & REF \\
\hline $\mathrm{p}^{ \pm}$ & $<0.001$ & $<0.001$ & \\
\hline \multicolumn{4}{|c|}{$\begin{array}{l}\text { *50 cases had missing PAM50 subtype, } 17 \text { cases had missing ROR-PT. Abbreviations: estrogen receptor (ER), } \\
\text { relative frequency difference (RFD), risk of recurrence, proliferation and tumor size weighted (ROR-PT), standard } \\
\text { deviation (SD), wild type (WT) }\end{array}$} \\
\hline \multicolumn{4}{|l|}{${ }^{\dagger}$ Adjusted for age and race. } \\
\hline \multicolumn{4}{|l|}{ Two-sided Chi-square test. } \\
\hline \multicolumn{4}{|c|}{${ }^{\S}$ ER-negative defined as ESR1 mRNA level $<8.77$, ER-positive defined as ESR1 mRNA $\geq 8.77$. } \\
\hline
\end{tabular}


Table 3: Associations of patient and clinical characteristics with high-risk genomic features among estrogen receptor (ER)-borderline tumors in Carolina Breast Cancer Study Phases 1, 2, and 3

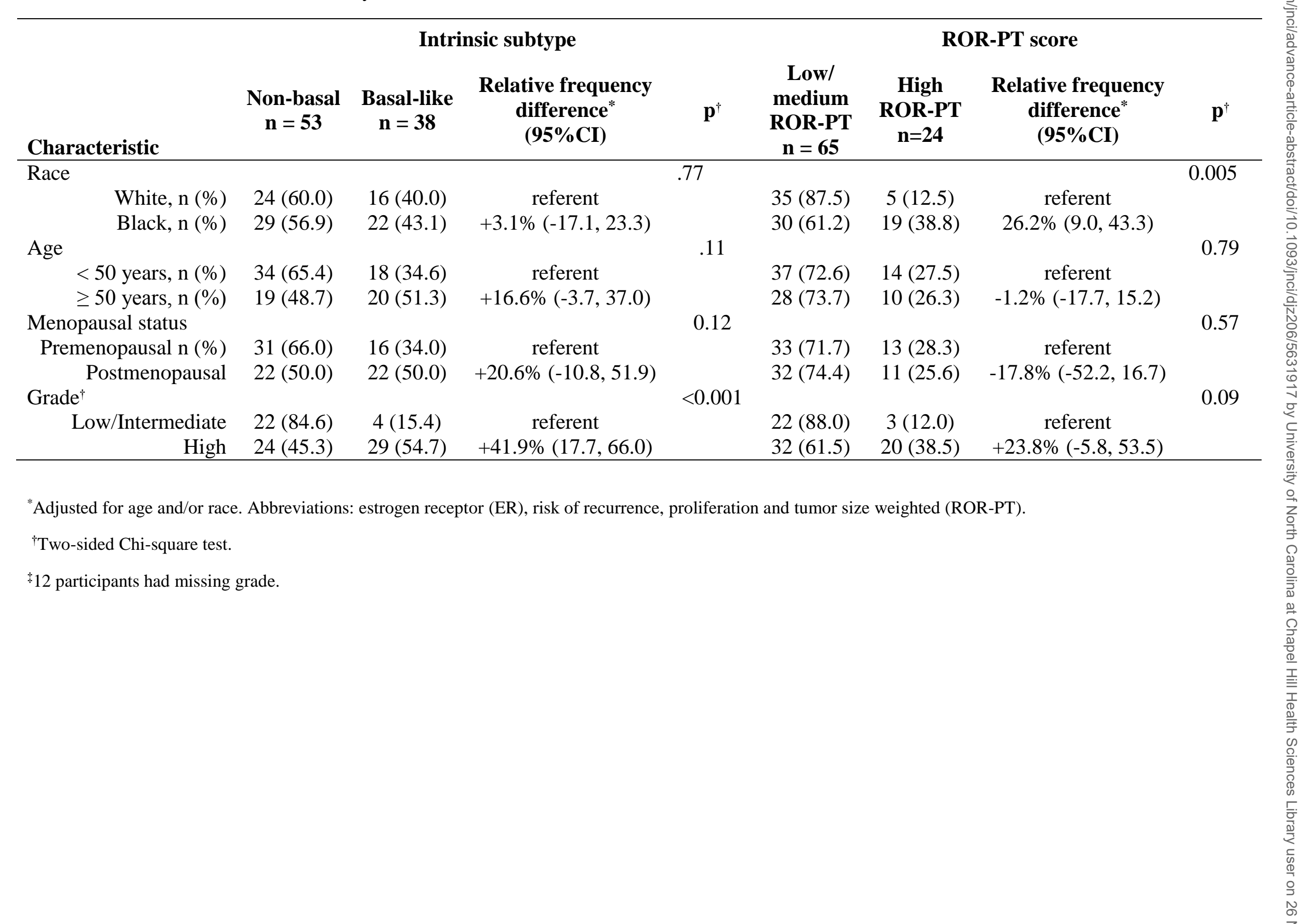


Table 4: Adjusted hazard ratios (HR) for disease-free interval among HER2-negative cases by estrogen receptor (ER) category and endocrine therapy receipt in Carolina Breast Cancer Study Phase 3.

\begin{tabular}{|c|c|c|c|c|c|c|c|}
\hline \multirow[b]{2}{*}{ Group } & \multirow{2}{*}{$\begin{array}{c}\text { N } \\
\text { (No. of } \\
\text { recurrences) }\end{array}$} & \multicolumn{2}{|c|}{ All } & \multicolumn{2}{|c|}{ White } & \multicolumn{2}{|c|}{ Black } \\
\hline & & $\begin{array}{l}\text { Reduced } \\
\text { Model }^{*}\end{array}$ & Full Model ${ }^{\dagger}$ & $\begin{array}{l}\text { Reduced } \\
\text { Model }^{*}\end{array}$ & Full Model ${ }^{\dagger}$ & $\begin{array}{l}\text { Reduced } \\
\text { Model }^{*}\end{array}$ & Full Model ${ }^{\dagger}$ \\
\hline \multicolumn{8}{|l|}{ ER-positive } \\
\hline HR $(95 \% \mathrm{CI})$ & $1064(95)$ & $\begin{array}{c}1.00 \\
\text { (Reference) }\end{array}$ & $\begin{array}{c}1.00 \\
\text { (Reference) }\end{array}$ & $\begin{array}{c}1.00 \\
\text { (Reference) }\end{array}$ & $\begin{array}{c}1.00 \\
\text { (Reference) }\end{array}$ & $\begin{array}{c}1.00 \\
\text { (Reference) }\end{array}$ & $\begin{array}{c}1.00 \\
\text { (Reference) }\end{array}$ \\
\hline $\mathrm{p}^{\S}$ & & -- & -- & -- & -- & -- & -- \\
\hline \multicolumn{8}{|l|}{$\begin{array}{l}\text { ER-borderline, no } \\
\text { endocrine therapy }\end{array}$} \\
\hline HR $(95 \% \mathrm{CI})$ & $45(13)$ & $\begin{array}{l}3.27(1.83, \\
5.86)\end{array}$ & $\begin{array}{l}3.33(1.84, \\
\quad 6.02)\end{array}$ & $\begin{array}{l}4.78(2.03, \\
11.29)\end{array}$ & $\begin{array}{l}4.22(1.75 \\
\quad 10.23)\end{array}$ & $\begin{array}{c}2.29(1.03, \\
5.11)\end{array}$ & $\begin{array}{l}2.53(1.13, \\
5.70)\end{array}$ \\
\hline $\mathrm{p}^{\S}$ & & $<0.001$ & $<0.001$ & $<0.001$ & 0.001 & 0.04 & 0.02 \\
\hline \multicolumn{8}{|l|}{$\begin{array}{l}\text { ER-borderline, } \\
\text { endocrine therapy }\end{array}$} \\
\hline HR $(95 \% \mathrm{CI})$ & $30(6)$ & $\begin{array}{l}2.01(0.88 \\
\quad 4.60)\end{array}$ & $\begin{array}{c}2.03(0.89, \\
4.65)\end{array}$ & $\begin{array}{c}1.00(0.14, \\
7.29)\end{array}$ & $\begin{array}{l}0.99(0.14 \\
7.19)\end{array}$ & $\begin{array}{l}2.55(1.01 \\
\quad 6.44)\end{array}$ & $\begin{array}{c}2.77(1.09, \\
7.04)\end{array}$ \\
\hline $\mathrm{p}^{\S}$ & & 0.10 & 0.09 & 0.99 & 0.99 & 0.048 & 0.03 \\
\hline \multicolumn{8}{|l|}{ ER-negative: } \\
\hline HR (95\%CI) & $309(75)$ & $\begin{array}{l}2.41(1.77 \\
3.28)\end{array}$ & $\begin{array}{l}2.45(1.77 \\
3.41)\end{array}$ & $\begin{array}{c}2.63(1.59 \\
4.35)\end{array}$ & $\begin{array}{l}2.36(1.39 \\
4.02)\end{array}$ & $\begin{array}{l}2.14(1.43, \\
\quad 3.21)\end{array}$ & $\begin{array}{c}2.42(1.57 \\
3.74)\end{array}$ \\
\hline $\mathrm{p}^{\S}$ & & $<0.001$ & $<0.001$ & $<0.001$ & 0.002 & $<0.001$ & $<0.001$ \\
\hline
\end{tabular}

*Adjusted for age, stage. Abbreviations: hazard ratio (HR), estrogen receptor (ER), human epidermal growth factor receptor 2 (HER2).

${ }^{\dagger}$ Adjusted for age, stage, chemotherapy receipt

Included ER-positive cases received endocrine therapy, included ER-negative cases did not receive endocrine therapy.

§Two-sided Chi square test. 
Figure titles and legends

Figure 1. Intrinsic subtype distribution by estrogen receptor (ER) category in Carolina Breast Cancer Study Phases 1, 2, and 3. ER-negatives and ER-borderlines had a statistically significantly higher frequency of HER2-enriched (17.7\% ER-negative, RFD: $+67.5 \%, 95 \%$ CI 58.6, 76.4, p-value <0.001; 1.3\% ER-borderline, RFD: +27.2\%, 95\% CI 12.2, 42.2, p-value $<0.001$; two-sided Chi-square test ) and Basal-like subtypes (71.7\% ER-negative, RFD: +80.3\%, 95\% CI 76.1, 84.4, p-value < 0.001; 41.8\% ER-borderline, RFD: $+37.7 \%, 95 \%$ CI 27.1, 48.4, pvalue $<0.001$; two-sided Chi-square test ) relative to ER-positive (2.7\% HER2-enriched, 5.1\% Basal-like)

Figure 2. Kaplan Meier disease-free interval (DFI) curves among HER2-negative cases by estrogen receptor (ER) category in Carolina Breast Cancer Study Phase 3. Included ERpositive cases received endocrine therapy, included ER-negative cases did not receive endocrine therapy. Pairwise two-sided log-rank tests were performed with Bonferroni correction for multiple comparisons. ER-negative (ER-Neg) and ER-positive (ER-Pos) cases had statistically significantly different DFI ( $\mathrm{p}<0.001)$. Similarly, ER-borderline cases not receiving endocrine therapy (ER-BL, no ET) and ER-positive cases had statistically significantly different DFI (p $<0.001)$. All other pairwise comparisons were not statistically significant.

Figure 3. Kaplan Meier disease-free interval (DFI) curves among HER2-negative white women by estrogen receptor (ER) category in Carolina Breast Cancer Study Phase 3. Included ER-positive cases received endocrine therapy, included ER-negative cases did not 
receive endocrine therapy. Pairwise two-sided log-rank tests were performed with Bonferroni correction for multiple comparisons. ER-negative (ER-Neg) and ER-positive (ER-Pos) cases had statistically significantly different DFI ( $\mathrm{p}<0.001)$. All other pairwise comparisons were not statistically significant.

Figure 4. Kaplan Meier disease-free interval (DFI) curves among HER2-negative black women by estrogen receptor (ER) category in Carolina Breast Cancer Study Phase 3. Included ER-positive cases received endocrine therapy, included ER-negative cases did not receive endocrine therapy. Pairwise two-sided log-rank tests were performed with Bonferroni correction for multiple comparisons. ER-negative (ER-Neg) and ER-positive (ER-Pos) cases had statistically significantly different DFI ( $\mathrm{p}<0.001)$. All other pairwise comparisons were not statistically significant. 
Figure 1--FINAL

Figure 1.

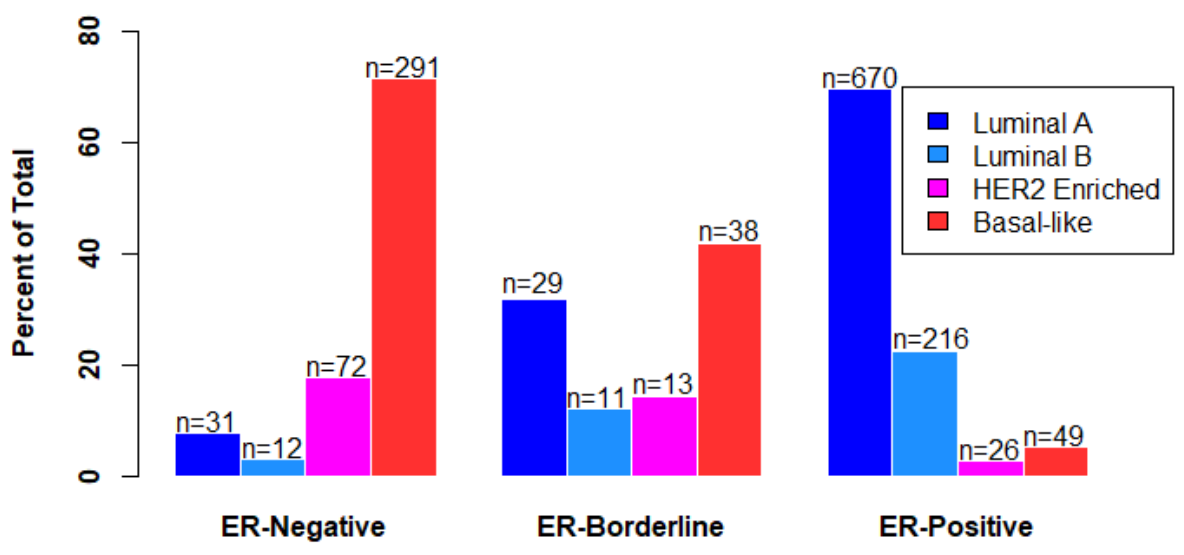


Figure 2.

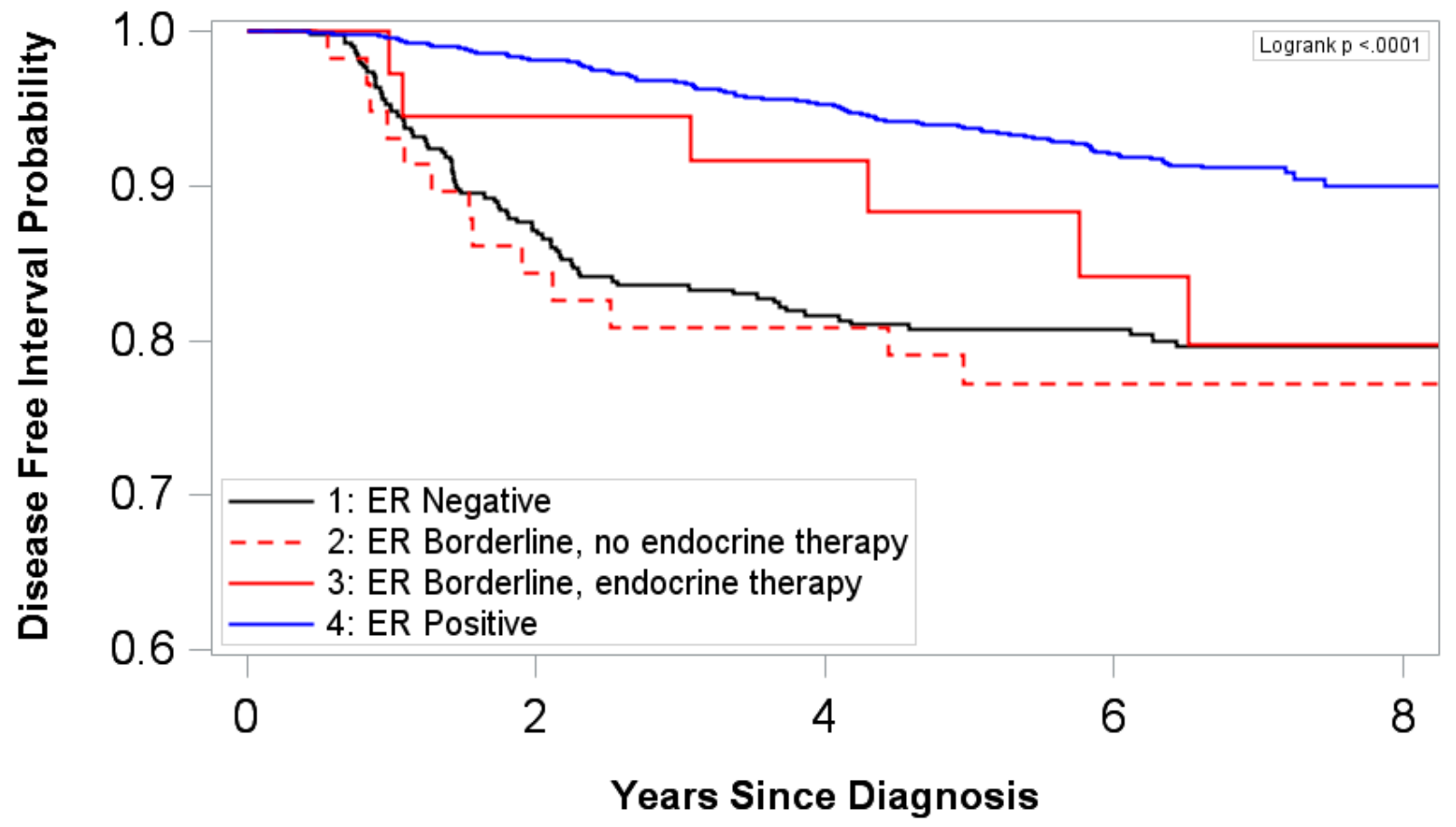

\begin{tabular}{r|c|ccccc} 
& No. at risk & \multicolumn{2}{l}{} & \\
& $\begin{array}{c}\text { Total } \\
\text { events }\end{array}$ & 0 & 2 & 4 & 6 & 56 \\
\hline ER-Neg & 75 & 384 & 325 & 280 & 225 & 4 \\
-- ER-BL, no ET & 13 & 58 & 48 & 45 & 34 & 6 \\
- ER-BL, ET & 6 & 36 & 33 & 29 & 19 & 133
\end{tabular}


Figure 3.

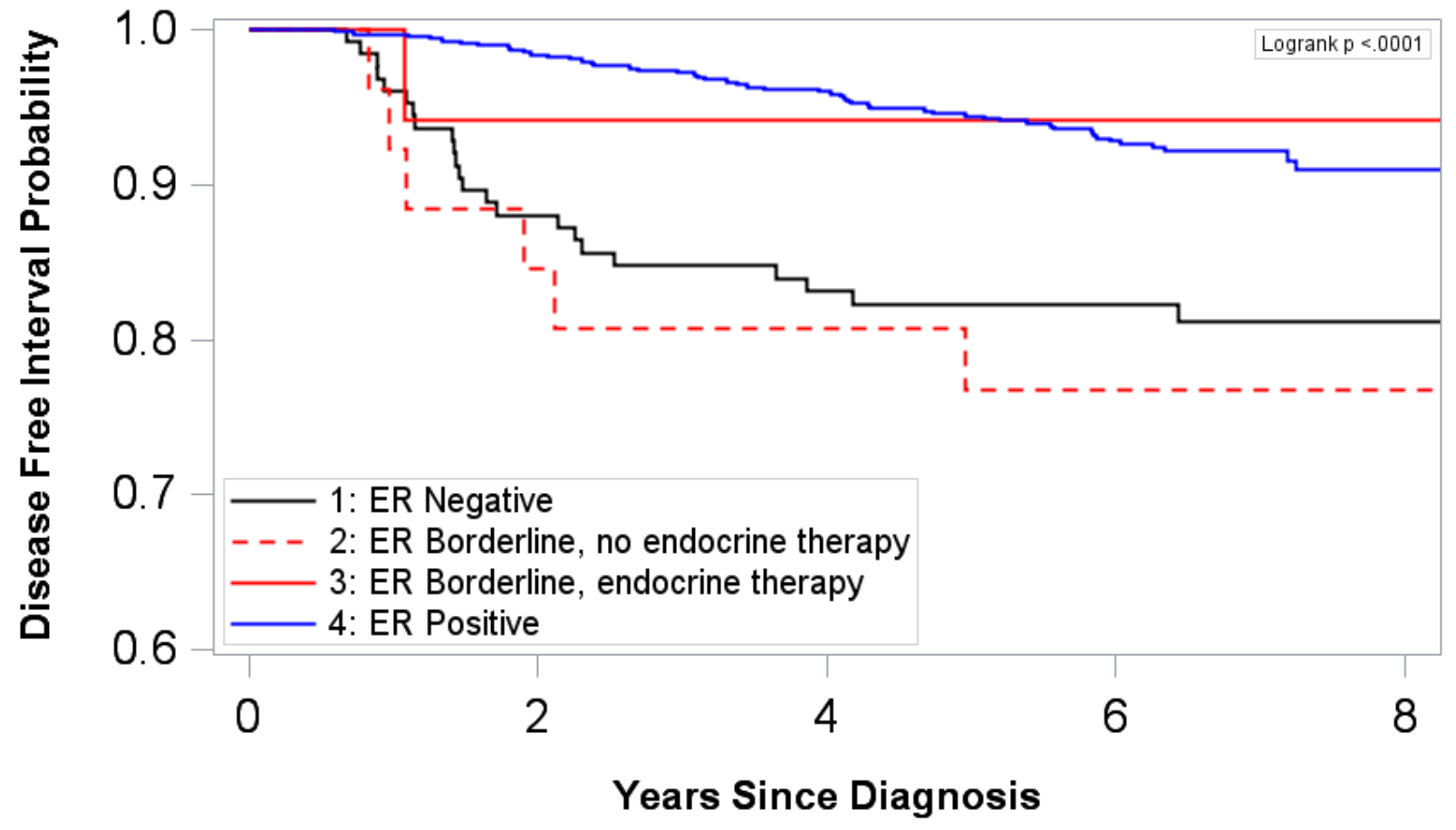

\begin{tabular}{r|c|ccccc} 
White women & Total & No. at risk & & & & \\
\\
& events & 0 & 2 & 4 & 6 & 80 \\
\hline ER-Neg & 23 & 126 & 110 & 99 & 16 & 4 \\
-- ER-BL, no ET & 6 & 26 & 22 & 16 & 9 & 1 \\
- ER-BL, ET & 1 & 17 & 671 & 623 & 456 & 79
\end{tabular}


Figure 4.

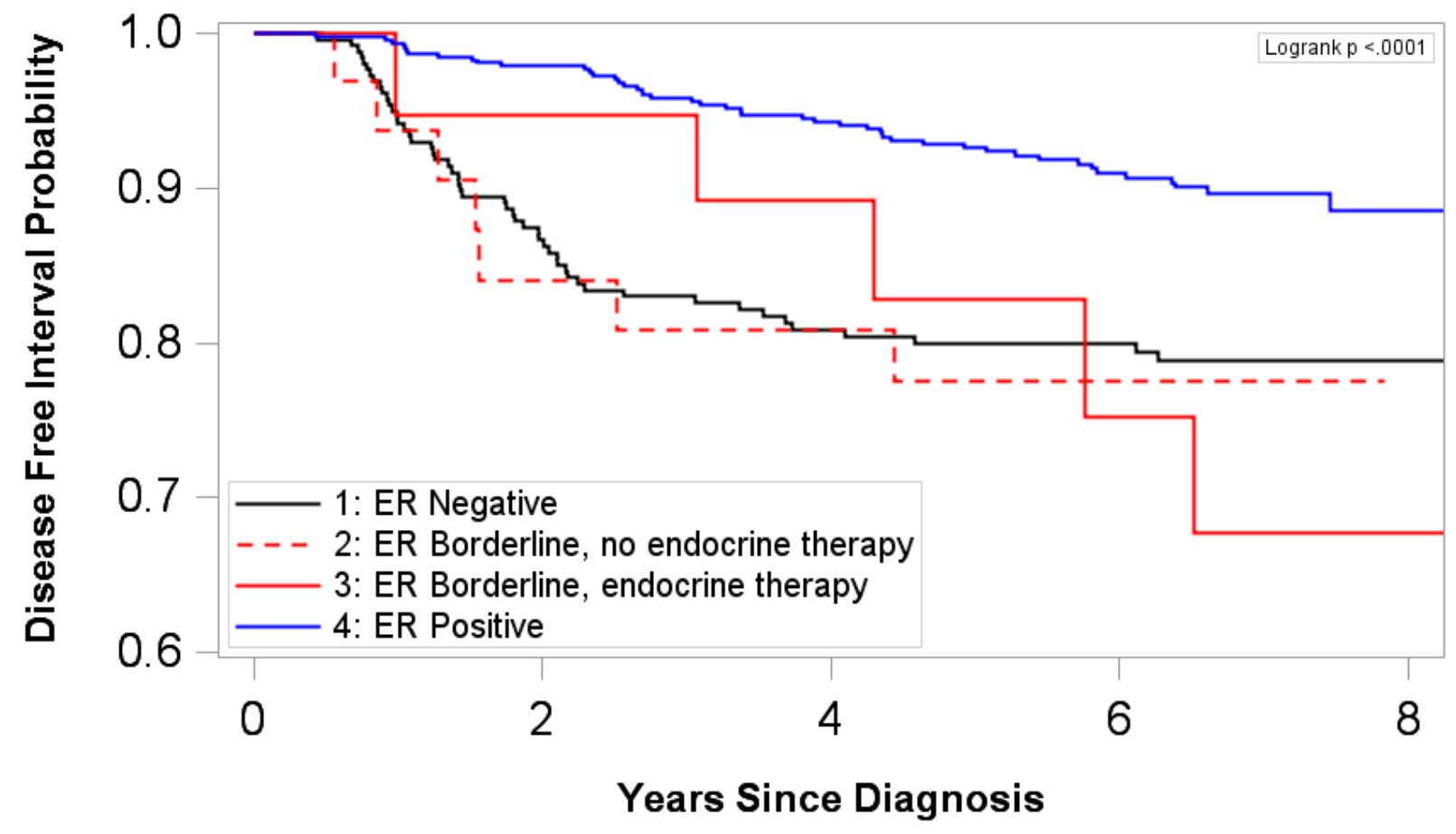

\begin{tabular}{r|c|ccccc} 
Black women & Total & No. at risk & & & & \\
\\
events & 0 & 2 & 4 & 145 & 36 \\
ER-Neg & 52 & 258 & 215 & 25 & 18 & 0 \\
-- ER-BL, no ET & 7 & 32 & 17 & 14 & 10 & 5 \\
- ER-BL, ET & 5 & 19 & 452 & 400 & 300 & 54
\end{tabular}

